\title{
Forecast of icing events at a wind farm in Sweden
}

\section{Davis, Neil; Hahmann, Andrea N.; Clausen, Niels-Erik; Zagar, Mark}

Published in:

Journal of Applied Meteorology and Climatology

Link to article, DOI:

10.1175/JAMC-D-13-09.1

Publication date:

2014

Document Version

Publisher's PDF, also known as Version of record

Link back to DTU Orbit

\section{Citation (APA):}

Davis, N., Hahmann, A. N., Clausen, N-E., \& Zagar, M. (2014). Forecast of icing events at a wind farm in Sweden. Journal of Applied Meteorology and Climatology, 53(2), 262-281. https://doi.org/10.1175/JAMC-D-1309.1

\section{General rights}

Copyright and moral rights for the publications made accessible in the public portal are retained by the authors and/or other copyright owners and it is a condition of accessing publications that users recognise and abide by the legal requirements associated with these rights.

- Users may download and print one copy of any publication from the public portal for the purpose of private study or research.

- You may not further distribute the material or use it for any profit-making activity or commercial gain

- You may freely distribute the URL identifying the publication in the public portal 


\title{
Forecast of Icing Events at a Wind Farm in Sweden
}

\author{
Neil Davis, Andrea N. Hahmann, AND Niels-ERiK Clausen \\ DTU Wind Energy, Roskilde, Denmark \\ MARK ŽAGAR \\ Vestas Wind Systems A/S, Aarhus, Denmark
}

(Manuscript received 20 December 2012, in final form 28 August 2013)

\begin{abstract}
This paper introduces a method for identifying icing events using a physical icing model, driven by atmospheric data from the Weather Research and Forecasting (WRF) model, and applies it to a wind park in Sweden. Observed wind park icing events were identified by deviation from an idealized power curve and observed temperature. The events were modeled using a physical icing model with equations for both accretion and ablation mechanisms (iceBlade). The accretion model is based on the Makkonen model but was modified to make it applicable to the blades of a wind turbine rather than a static structure, and the ablation model is newly developed. The results from iceBlade are shown to outperform a 1-day persistence model and standard cylinder model in determining the times when any turbine in the wind park is being impacted by icing. The icing model was evaluated using inputs from simulations using nine different WRF physics parameterization combinations. The combination of the Thompson microphysics parameterization and version 2 of the Mellor-Yamada-Nakanishi-Niino PBL scheme was shown to perform best at this location. The distribution of cloud mass into the appropriate hydrometeor classes was found to be very important for forecasting the correct icing period. One concern with the iceBlade approach was the relatively high false alarm rates at the end of icing events due to the ice not being removed rapidly enough.
\end{abstract}

\section{Introduction}

Onshore wind farms are one of the most cost-effective ways to generate electricity (Hau 2013), leading to their large role in the development of plentiful clean energy for the future. In many parts of the world, the most lucrative available sites for wind energy extraction have already been placed into production. This is forcing wind farm developers to look to sites that are more complex and carry additional risks or uncertainties, such as offshore, forested, and cold climate locations. As of 2012, wind parks in cold climates account for approximately $4.1 \%$ of the $240 \mathrm{GW}$ of global wind energy capacity (Ronsten et al. 2012). For wind parks in cold climates, one of the largest sources of risk comes from atmospheric icing on the turbine blades.

Atmospheric icing occurs on all structures that are exposed to moisture at temperatures below $0^{\circ} \mathrm{C}$. There

Corresponding author address: Neil Davis, Dept. of Wind Energy, Technical University of Denmark, Ris $\varnothing$ Campus, Frederiksborgvej 399, P.O. Box 49, 4000 Roskilde, Denmark.

E-mail:neda@dtu.dk have been extensive studies of atmospheric icing both on cylinders, largely related to overhead power lines summarized in Farzaneh (2008), and on airfoils, mostly in the aviation community (e.g., Gent et al. 2000; Bragg et al. 2005). The challenge of atmospheric icing has also been studied for wind energy, with several international collaborations on the topic (e.g., Fikke et al. 2006; Ronsten et al. 2012), as well as a dedicated conference on wind energy in cold climates (Winterwind International Wind Energy Conference). The use of mesoscale models to estimate icing has been applied for studies in aviation (e.g., Thompson et al. 1997; Wolff et al. 2009), for both power-line icing and turbine icing in the power industry (e.g., Fikke et al. 2008; Dierer et al. 2011), and for comparisons with icing on standard cylinders (Bernstein et al. 2012; Byrkjedal 2012a,b; Soderberg and Baltscheffsky 2012; Yang 2012).

There are three main types of atmospheric icing: 1 ) incloud icing is generated by supercooled water droplets in clouds or fog that contact a surface and freeze upon impact, often leading to rime ice that has a rough appearance and milky look due to trapped air that decreases its density; 2) freezing rain occurs when rain falls 
onto structures with temperatures below $0^{\circ} \mathrm{C}$, commonly forming glaze ice that has a high density and clear appearance; 3 ) wet snow icing occurs under special meteorological conditions that allow snow with a liquid surface to accumulate on structures when the ambient temperature is close to freezing. The focus of this study is on incloud icing only.

In-cloud icing on turbine blades increases the safety, financial, and maintenance risks when developing and operating a wind farm in cold climates. Accumulated ice on the blades can fall or be thrown from the turbine, requiring careful planning to minimize the risk to people and property near the wind farm (Seifert et al. 2003). The added mass, caused by the ice, places additional loads on the turbine that can lead to increased maintenance and shorten turbine lifetimes. Finally, ice accumulation changes the aerodynamic properties of the blades themselves and can lead to reduced energy production during the icing season. Homola et al. (2012) showed that the power curve (i.e., the relationship between wind speed and power) for a simulated wind turbine is reduced by around $28 \%$ between the cut-in wind speed, where the turbine is able to produce electricity, and the rated wind speed, where the turbine is producing its rated power output, for a turbine blade with moderate ice growth. Barber et al. (2011) investigated two wind farms in Switzerland and found that icing leads to a $2 \%$ loss of annual energy production (AEP) at a farm with moderate icing where the ice accumulation is not severe enough to lead to flow separation on the airfoil, and a 17\% loss in AEP at a farm that experiences extreme icing leading to flow separation.

Thus far, most research into icing on wind turbines has related to observations (e.g., Fikke et al. 2006; Ronsten et al. 2012), ice throw (e.g., Seifert et al. 2003; Cattin et al. 2007), and computational fluid dynamics (CFD) modeling focused on the type and amount of icing formed on the blades and the impact of that icing on airfoil performance under different fixed meteorological conditions (e.g., Makkonen et al. 2001; Homola et al. 2010a; Virk et al. 2010; Homola et al. 2012; Virk et al. 2012). There have been a few conference presentations on forecasting icing at Winterwind, but these have mostly focused on forecasting ice on a standard cylinder using the Makkonen (2000) model and then relating the standard icing results to the turbine using statistical algorithms (e.g., Dierer et al. 2011; Byrkjedal 2012a; Soderberg and Baltscheffsky 2012; Yang 2012). Bernstein et al. (2012) reported that the correlation between measured icing load on a cylinder and actual power loss is weak because significant ice loads may persist on cylinders while power recovers at the turbines. They also found that active icing is better correlated with power loss. The standard cylinder approach has been shown to reasonably capture the ice loading of a standard cylinder mounted near the turbine, but only limited agreement with the power output was found (Byrkjedal 2012a).

This study introduces the iceBlade model that was developed with the goal of providing a better relationship between the forecast periods of icing and reduced power output. This was accomplished by modifying the inputs to the Makkonen ice accretion model to better represent the conditions on the wind turbine blade, as well as including algorithms for ice sublimation, and a method for modeling total ice shedding. It will be shown that the results from the iceBlade model, driven by mesoscale model outputs, can successfully reproduce the periods of icing observed at a wind park in Sweden.

The rest of the paper is organized as follows. In section 2, the data from the wind park are described, and the method of determining icing from the observations values is presented. Section 3 describes the models used in this study, first presenting the iceBlade model, then the mesoscale model that provides the inputs to iceBlade, and finally the coupling of the two models. In section 4, the observations and model results are presented and discussed. In section 5, the main conclusions are presented.

\section{Wind farm data}

This study focuses on power production and meteorological data from a wind farm in central Sweden. The site is fairly noncomplex, with land use dominated by forest and small lakes. The farm consists of 48 Vestas Wind Systems A/S V90 turbines, and the dataset contains 10-min-average data for the month of January 2011. Data were missing for most turbines for the period between 16 and 19 January. In addition to the production and meteorological data, all turbines provided status counters. Two of these counters were used for quality assurance (QA) of the dataset. The first counter provided the number of seconds, out of the optimal $600 \mathrm{~s}$, that the wind was within the required range for producing power. This means that the wind speed was between the cut-in wind speed of $4 \mathrm{~m} \mathrm{~s}^{-1}$ and the cutoff wind speed of $25 \mathrm{~m} \mathrm{~s}^{-1}$, above which the turbine stops producing for safety reasons. The second counter provided the number of seconds the turbine was in normal operation. All time steps where either of these values deviated from the optimal value by more than $10 \mathrm{~s}$ were flagged as QA time steps and dropped from the analysis. To form a more homogeneous dataset, five turbines were removed from the analysis. This left 43 turbines to represent the wind farm in the study.

Each turbine reported instantaneous meteorological measurements from its nacelle for wind direction, wind 


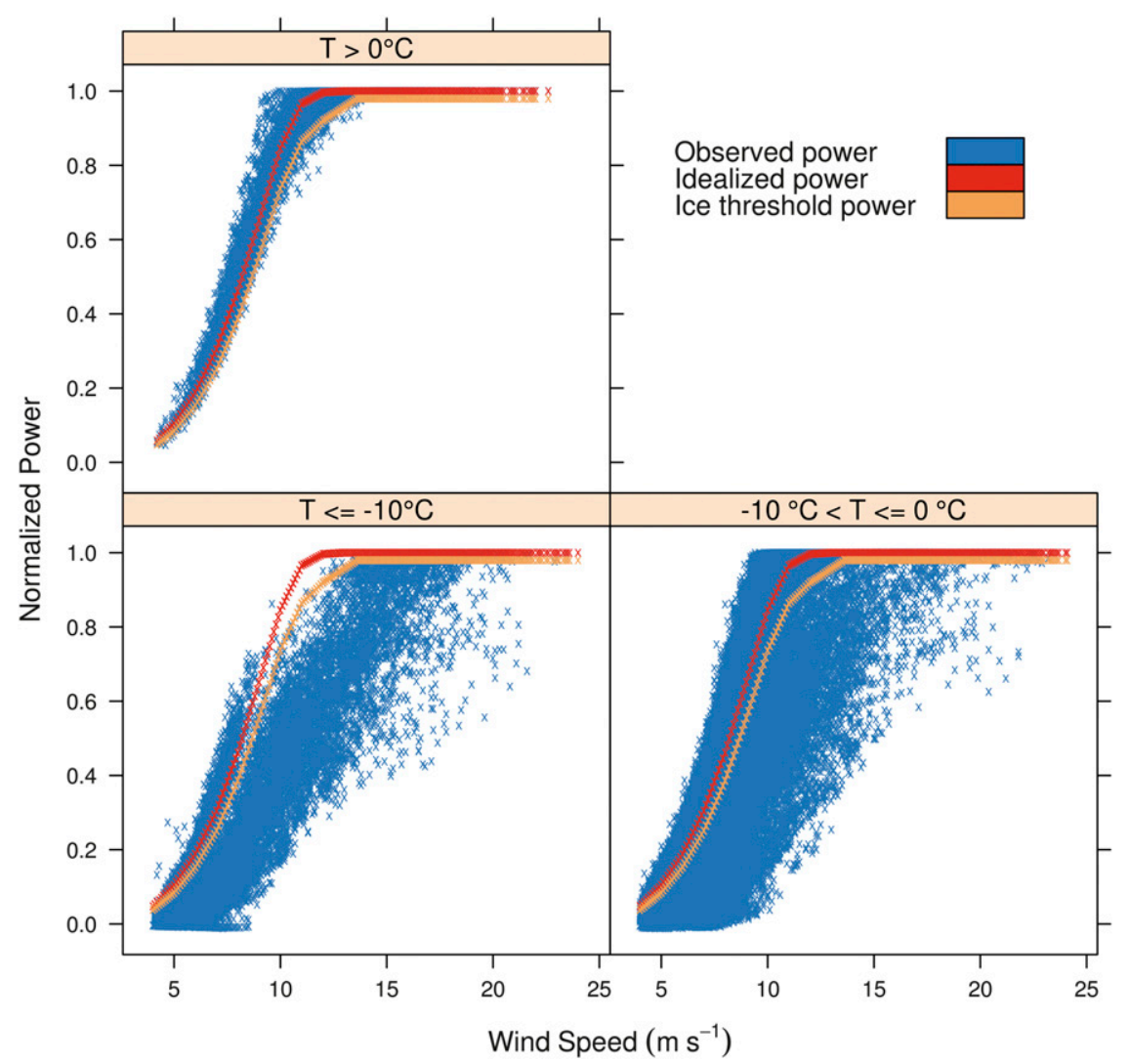

FIG. 1. Idealized (red or orange) and observed (blue) power curves for each turbine in the wind park: red curves show the idealized power curve as provided by WAsP data tables for the unadjusted nacelle wind speeds, and orange curves show the threshold used for observed icing events defined in (1). The panels represent various temperature bins: (top) $T>0^{\circ} \mathrm{C}$, (bottom right) $-10^{\circ}<T \leq 0^{\circ} \mathrm{C}$, and (bottom left) $T \leq 10^{\circ} \mathrm{C}$.

speed, wind speed standard deviation, and temperature. Only temperature and wind speed were used in this study. The temperature measurements had a rather coarse precision of $1^{\circ} \mathrm{C}$ created by rounding the decimal observations. The measured wind speed data were already adjusted to account for the speedup experienced due to the placement of the anemometer on the nacelle. Also, as the wind speed was taken at the turbine, any wake loss is already accounted for in the wind speed so no additional modification is required.

An idealized power curve for the V90 turbine was calculated using data provided by the Wind Atlas Analysis and Application Program, version 10 (WAsP; Troen and Petersen 1989), to evaluate the turbine performance. Figure 1 compares the observed power curve for all 43 turbines with two idealized curves for three different temperature bins (above $0^{\circ} \mathrm{C}$, from $0^{\circ}$ to $-10^{\circ} \mathrm{C}$, and below $-10^{\circ} \mathrm{C}$ ). The idealized curves represent 1 ) the unadjusted idealized power curve calculated using the raw nacelle wind speed and 2) a fitted curve for the ice threshold defined below. The observed power curve shows good agreement with the idealized power curves when the temperature was above $0^{\circ} \mathrm{C}$, with similar spread on each side of the power curve. However, for temperatures less than or equal to $0^{\circ} \mathrm{C}$ the observed yield was consistently lower than the estimated value from the idealized power curve. Very few points fell above the idealized curves; for the coldest temperature bin, this suggests that the turbines were iced during the entire period when the temperature was below $-10^{\circ} \mathrm{C}$. It is expected that this feature would not be seen with a larger dataset that contained more points with temperatures lower than $-10^{\circ} \mathrm{C}$.

As there were no direct icing observations for any of the turbines, a proxy dataset was created. This was done by fitting a curve to the bottom of the observed power curve for temperatures above $0^{\circ} \mathrm{C}$ (blue curve in Fig. 1). This curve is calculated as 


$$
f(p)=p \times 0.8+\left[v^{3} / \max \left(v^{3}\right)\right],
$$

where $p$ is the idealized power at a given wind speed and $v$ is the wind speed. The threshold power $f(p)$ was limited to a maximum value of 0.98 . The curve allowed for a transition between a high deviation value of $20 \%$ at wind speeds below the rated wind speed $\left(12 \mathrm{~m} \mathrm{~s}^{-1}\right)$ when the power curve has a steep slope, and therefore a larger deviation, and the flat portion of the curve above the rated wind speed, where there is less variation in the power output. Using the icing threshold curve calculated in Eq. (1), an icing observation was defined as a data point that fell below that curve when the temperature was less than $0^{\circ} \mathrm{C}$. This assumes that all of the power loss observed at cold temperatures was the result of icing. This is a reasonable assumption, as at colder temperatures an increase in yield is typically expected due to the increased air density. Vertical wind shear is also expected to increase at cold temperatures; however, Antoniou et al. (2009) found that wind shear causes less than the $20 \%$ impact that we are using as our icing cutoff.

Because of the large variability in icing from each of the 43 turbines, three different wind park icing occurrence time series, representing different numbers of affected turbines, were created: 1) ANY was considered to have occurred when any of the 43 turbines in the park experienced icing, 2) MOST wind park icing was considered to have occurred when the majority $(>50 \%)$ of active turbines had icing events, and 3) ALL wind park icing was considered to have occurred when all active turbines had icing events.

The temperature and wind speed values from the turbines were also examined. The temperature data showed an average spread of $2.6^{\circ} \mathrm{C}$ across the 43 turbines. There was also one turbine that was a clear outlier at the beginning of the period; excluding that turbine reduces the spread to $2.5^{\circ} \mathrm{C}$. The wind speed also had a very large mean spread of $5.14 \mathrm{~m} \mathrm{~s}^{-1}$. This spread was likely due to the micro-siting of the turbines, where several turbines were placed in areas where the wind was increased due to local effects. Given the large spread of the data and the existence of outliers in the dataset, the median temperature and wind speed were chosen to compare with the model data.

The National Centers for Environmental Prediction Automated Data Processing Global Upper Air and Surface Weather Observations dataset (documented and available online at http://rda.ucar.edu/datasets/ ds337.0/) was used as an independent meteorological dataset for additional mesoscale model verification. From this dataset, three surface stations located within $100 \mathrm{~km}$ of the wind farm were chosen (Fig. 2, inset). The surface stations recorded station pressure, specific humidity, temperature, and wind speed, and provided a more detailed model evaluation than was possible using only the wind park data. The surface stations have been renamed from south to north as stations A, B, and C. Station A is located on a small island in a large lake, station $\mathrm{B}$ is located in a field with forest nearby, and station $\mathrm{C}$ is located next to a river surrounded by grasslands and forest.

From the ANY icing observation dataset, a baseline persistence model was created for comparison with the iceBlade model. This model used a 1-day forecast, where missing data were treated as an unavailable forecast. Given the relatively long time periods of the icing and nonicing events in this dataset (Fig. 3), it is presumed that the persistence model would be difficult to beat. However, it should be noted that for other locations and periods the persistence model may not perform as well.

\section{Models}

\section{a. The iceBlade icing model}

The iceBlade model is a new model developed to approximate the mass of ice that accumulates on a wind turbine blade during in-cloud icing conditions. The model is presently designed to only estimate the effects of liquid-phase cloud particles accreting on a simplified blade represented by a cylinder, with an incoming velocity based on the rotational speed of a wind turbine under similar conditions. The model presently neglects wet snow icing, which may be significant at certain locations, but did not appear to be important for this particular wind farm. IceBlade consists of the Makkonen (2000) accretion model, with inputs suitable for wind turbines, and ablation models for sublimation and shedding. The accretion and the ablation models are described in the next two sections. The representation of the turbine in the model is described in section $3 a(3)$.

\section{1) ICE ACCRETION MODEL}

Makkonen (2000) presented a model to calculate the rate of ice mass growth based on the mass flux of cloud particles (a product of the mass concentration of particles $\omega$, the velocity, and the cross-sectional area of the object $A$ ) and three correction factors $\alpha_{1}, \alpha_{2}$, and $\alpha_{3}$ :

$$
\frac{d M}{d t}=\alpha_{1} \alpha_{2} \alpha_{3} \omega v A
$$

The correction factors, which can range in value from 0 to 1 , represent processes that reduce the amount of ice accretion from its maximum value, the incoming mass flux. These factors are defined as efficiencies of collision $\left(\alpha_{1}\right)$, sticking $\left(\alpha_{2}\right)$, and accretion $\left(\alpha_{3}\right)$. The usage of 


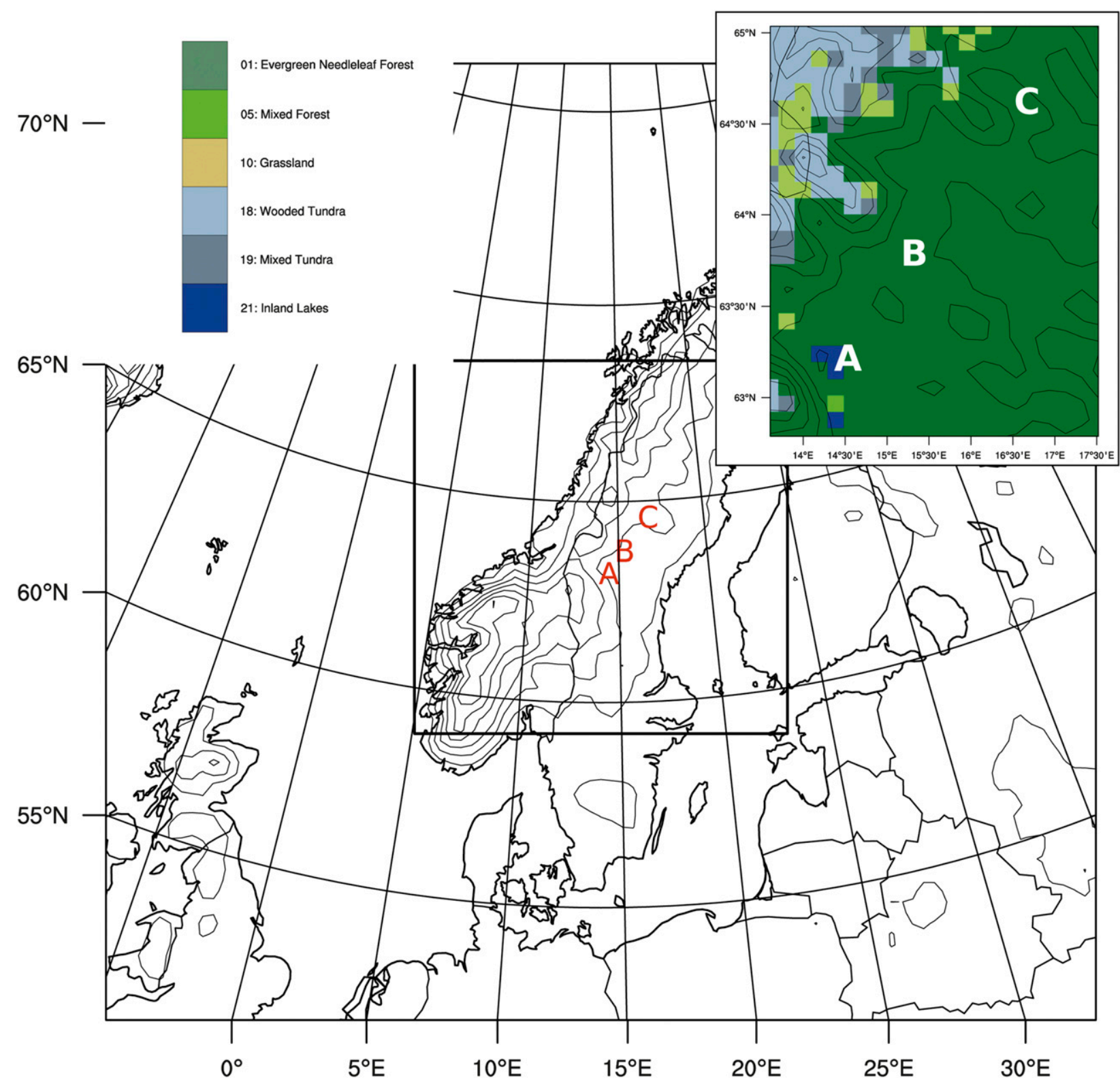

FIG. 2. Terrain contours from 0 to $1600 \mathrm{~m}$ with 200-m intervals for the outer WRF domain. The inner WRF domain is marked by the rectangle, and the wind park location is identified by a black circle. The inset map shows a zoomed-in region of the domain around the three meteorological stations, showing the WRF land use from the inner nest, and contours from 100 to 900 with 100 -m intervals.

efficiency factors allows for different models to be constructed quickly by replacing the factors with updated methods, allowing for the easy extension of the model to new areas of research. IceBlade uses the unmodified factors at present; therefore, only a simple description of each is provided below.

The collision efficiency term $\alpha_{1}$ represents the total collision efficiency $E$. This value can be calculated using an empirical formula [Eq. (1) in Finstad et al. (1988)] derived using regression analysis based on data from an investigation of water droplets in flows around cylinders by Langmuir and Blodgett (1961). In addition to $E$, Finstad et al. (1988) derived relationships for calculating the maximum impingement angle $\alpha_{\max }$, stagnation line velocity $v_{0}$, and stagnation line collision efficiency $\beta_{0}$. The integration of all collision efficiencies between $\pm \alpha_{\max }$ is represented by $E$.

The sticking efficiency term $\alpha_{2}$ approximates the loss of incoming cloud particles that either bounce off the structure (frozen) or generate splash, which reduces the 

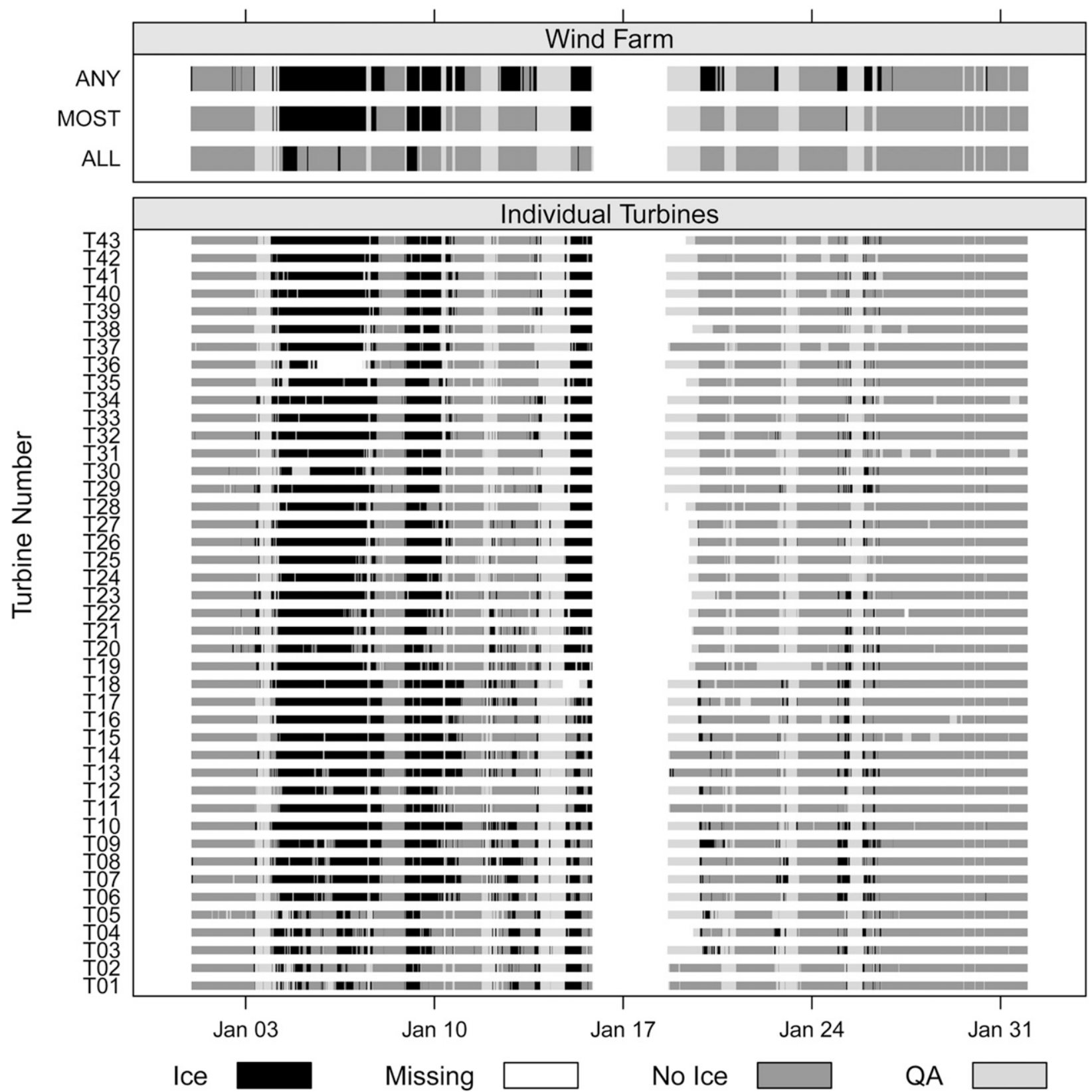

FIG. 3. (top to bottom) Time series of observed icing for ANY, MOST, and ALL turbines and for each (T43-T01) turbine. White space denotes a period for which turbine data were not available, light gray indicates data obtained when the turbine was not in optimal operation for the full 10-min period, dark gray denotes periods during which there was no icing, and black shows icing periods.

mass available for accretion. From Makkonen (2000), the loss from supercooled water droplets is almost zero, corresponding to an $\alpha_{2}$ of 1 . As iceBlade is designed for modeling work with liquid droplets only at present, $\alpha_{2}$ is always set to 1 .

The final efficiency term $\alpha_{3}$ estimates the ratio of incoming mass that freezes upon impact with the structure. During rime icing conditions all impacting particles freeze, leading to an $\alpha_{3}$ value of 1 . Under glaze icing conditions only a portion of the incoming mass freezes. The amount of mass that is frozen is controlled by the heat balance at the interface between the incoming droplets and the surface. In Makkonen (2000), this is represented by

$$
Q_{f}+Q_{v}=Q_{c}+Q_{e}+Q_{l}+Q_{s}
$$

where $Q_{f}$ is the latent heat released during freezing, $Q_{v}$ is the frictional heating of air, $Q_{c}$ is the loss of sensible 
heat to the air, $Q_{e}$ is the heat lost to evaporation, $Q_{l}$ is the heat loss in warming the impinging water to the freezing temperature, and $Q_{s}$ is the heat loss due to radiation. The terms in Eq. (3) have been parameterized in Makkonen (2000) and will not be replicated here. In our experience, the efficiency term $\alpha_{3}$ defined using the parameterizations of Eq. (3), can be applied to both rime and glaze icing situations, provided the result is limited to a range of 0 to 1 .

Based on the assumptions presented above, there are two inherent limitations of the Makkonen model as applied in iceBlade:

(i) the model is applicable only to cylindrical objectsthis also implies that the ice shape itself retains a cylindrical shape as it grows, and

(ii) the model is applicable only to supercooled water droplets.

\section{2) ICE ABLATION MODELS}

Ice ablation refers to all processes that remove ice from a structure. There are three main ablation processes: 1) melting, 2) sublimation, and 3) shedding. Melting and sublimation are physical processes that are based on the heat and moisture balance between the ice and the ambient air when the temperature is above and below the freezing point. Ice shedding occurs when ice falls from the structure due to a loss of adhesion. For a section of the structure, ice shedding can be described as either total shedding, where the entire mass of accumulated ice is removed from the structure, or partial shedding, where the ice loses cohesion with another part of the ice, rather than losing adhesion to the structure. IceBlade includes algorithms for sublimation and total shedding described in detail below.

Total ice shedding is based on microscopic interactions between ice and the blade surface, and its modeling requires detailed information about the blade surface and the way the ice accumulated on that surface. Since one of the design parameters of iceBlade is the application to different turbines under various conditions, it was decided that the implementation of a physical shedding algorithm was too turbine specific and currently outside of the model's scope. Therefore, a simplified method was developed based on the following assumptions: 1) when a turbine is in operation, even a slight loss in adhesion would cause the ice to be thrown from the turbine due to the forces present on the rotating blade; 2) the only loss of adhesion is due to melting at the blade surface; and 3) the turbine is always operating according to the idealized power curve. These assumptions greatly underestimate the shedding that occurs since it can often happen at temperatures below $0^{\circ} \mathrm{C}$, due to turbulence, or blade flexing. Given those assumptions, total shedding is implemented by removing all ice from the blade when the ambient temperature is above $0.5^{\circ} \mathrm{C}$ for $1 \mathrm{~h}$. This threshold was tested at this location and found to be reasonable; however, it may need to be modified for other sites. Because of the relatively low temperature threshold for total shedding, ice melt is not included in the iceBlade model at this time.

Ice sublimation is modeled using the explicit solution [Eq. (16) from Srivastava and Coen (1992)]. To account for the change in shape, from spherical to cylindrical, the following modifications were made to Eq. (6) in Srivastava and Coen (1992):

$$
\left(\frac{d m}{d t}\right)_{1}=\frac{4 \pi r D f_{v} \rho_{s}\left(T_{\infty}\right)}{1+\frac{L_{s} D f_{v}}{k f_{h}} \rho_{s}^{\prime}},
$$

where $D$ is the diffusivity of water vapor in air, $f_{v}$ is the ventilation coefficient for water vapor, $\rho_{s}\left(T_{\infty}\right)$ is the saturation vapor density at ambient air temperature $\left(T_{\infty}\right), L_{S}$ is the latent heat of sublimation, $k$ is the thermal conductivity of air, $f_{h}$ is the ventilation coefficient for heat, and $\rho_{s}^{\prime}$ is the differentiation of $\rho_{s}\left(T_{\infty}\right)$. From Pruppacher and Klett (2004) it can be found that $2 f_{v}=$ Sh and $2 f_{h}=\mathrm{Nu}$, where Sh is the Sherwood number and $\mathrm{Nu}$ is the Nusselt number. The Sherwood and Nusselt numbers are dimensionless numbers that provide the ratio between convective and conductive transfers of mass and heat, respectively. The Sherwood number is defined as

$$
\mathrm{Sh}=K L / D,
$$

where $K$ is the mass transfer coefficient and $L$ is a characteristic length. For a sphere, $L$ is typically the diameter. By using Eq. (5) and substituting for $f_{v}$ and $f_{h}$, Eq. (4) can be rewritten as

$$
\left(\frac{d m}{d t}\right)_{1}=\frac{A \operatorname{Sh} D \rho_{s}\left(T_{\infty}\right)}{L\left(1+\frac{L_{s} D \operatorname{Sh}}{k \mathrm{Nu}} \rho_{s}^{\prime}\right)},
$$

where $A$ is the surface area as in Eq. (2). Sherif et al. (1997) presented a formula for the Nusselt number of an airfoil as a function of its chord length and leading-edge diameter, using the Reynolds and Prandtl numbers. Using this same formula, it is possible to calculate the Sherwood number by substituting the Schmidt number with the Prandtl number. The iceBlade sublimation equation is found by combining these calculations of the Sherwood and Nusselt numbers with Eq. (6), while using the chord length as the characteristic length $L$. The chord 
length term cancels out between the two equations allowing a constant value of 1.0 to be used in iceBlade.

\section{3) Turbine REPRESENTATION}

To reduce the complexity of the model, several simplifications have been made to the representation of a fully rotating turbine blade. IceBlade models a 1-m-long segment of the turbine blade as a cylinder, located approximately $85 \%$ down the length of the $41-\mathrm{m}$-long blade. Since specific information about the airfoil used on the turbines in this study was unavailable, a cylinder diameter of $0.144 \mathrm{~m}$ was taken from the National Renewable Energy Laboratory's 5-MW reference turbine (Jonkman et al. 2009). The cylinder diameter is based on the leading-edge radius for the airfoil being $2.4 \%$ of the chord length, with a chord length of $3.0 \mathrm{~m}$.

Rather than represent the blade as rotating through space, the iceBlade model was designed so that the blade is always located in the same meteorological conditions. This eliminates the calculation of how much time the blade segment spends at various points in the rotor plane. How this relates to the mesoscale modeling, and its impact on this study, are discussed in more detail in section $3 \mathrm{c}$.

The largest difference between the rotating turbine blade and a standard cylinder is the incoming velocity term. Since the blade is rotating at tip speeds approaching $90 \mathrm{~m} \mathrm{~s}^{-1}$, the ambient wind speed has to be converted to a blade-relative velocity. Again, the data required to calculate an appropriate revolutions-per-minute (rpm) curve were unavailable for the turbines at the studied site, so a generic curve based solely on the ambient wind speed was used in its place. The rpm value was then converted into a linear speed at a distance of $34.85 \mathrm{~m}$ from the center of rotation. In initial tests (not shown), it was found that this change reduced the number of icing events but increased the amount of ice accumulated during events when icing did occur. This is likely due to an increase in mass flux resulting from the increased velocity. The increased flux decreases the $\alpha_{3}$ term in Eq. (2), reducing or preventing ice growth at temperatures near or above $0^{\circ} \mathrm{C}$. However, when the ambient temperature is cold enough to freeze the increased mass flux, ice will accumulate more rapidly.

The final change between iceBlade and the Makkonen model for a standard cylinder is that the iceBlade model does not update the size of the cylinder between time steps. When the Makkonen model is run on a standard cylinder, it is assumed that the cylinder will retain its shape and therefore the change in diameter can be reasonably calculated from the ice mass and density. For the turbine blade, which is always orientated in one direction, most of the ice grows out of the leading edge, as seen in the CFD study by Homola et al. (2010b). This suggests that the ice growth simply extends the chord length rather than making the leading edge thicker and therefore would not have a significant impact on either the collision efficiency or the surface area facing the flow.

\section{b. Meteorological modeling}

Meteorological modeling for this study was undertaken using the Weather Research and Forecasting (WRF) mesoscale model, version 3.3 (Skamarock et al. 2008). This model has been shown to accurately represent the liquid water content of low-level clouds at high resolutions; however, questions remain about its ability to represent the size of the cloud particles via their median volumetric diameter (MVD) (Nygaard et al. 2011). The WRF model was driven with initial and boundary conditions from the Global Forecast System's Final Analysis Product (FNL), with sea surface temperatures from the National Oceanic and Atmospheric Administration's Optimum Interpolation Sea Surface Temperature dataset (OISST), version 2 (Reynolds et al. 2007). The FNL data were also used as input to grid four-dimensional data assimilation nudging on the outer nest. The nudging was applied on all levels above level 15, approximately $500 \mathrm{~m}$, with all nudging coefficients set to $7.5 \times$ $10^{-5}$. The nudging was not included below level 15 because of the increased influence of mesoscale features near the surface. The simulation was run for 30 days, in three 10-day periods, with $24 \mathrm{~h}$ of spinup per period. Two modeling domains were run, with the outer domain having a grid spacing of $30 \mathrm{~km}$ and the inner domain with grid spacing of $10 \mathrm{~km}$. The wind farm was located near the center of both domains (Fig. 2). Sixty-three vertical levels were used, 26 of which were within the lowest $1000 \mathrm{~m}$.

The physics options of the model were the defaults of the Rapid Radiative Transfer Model longwave radiation scheme (Mlawer et al. 1997), the Dudhia shortwave radiation scheme (Dudhia 1989), the Noah land surface model (Chen and Dudhia 2001), and the Kain-Fritsch cumulus parameterization scheme (Kain 2004), with three microphysics and three PBL schemes tested in a sensitivity matrix leading to a total of nine sensitivity simulations. For microphysical schemes, the Stony Brook University-Y. Lin (SBU-YLin; Lin and Colle 2011), Thompson (Thompson et al. 2008), and WRF single-moment five-class cloud microphysics (WSM5; Hong et al. 2004) schemes were selected. These schemes provided a good range of complexity, with the Thompson scheme having the most predictive variables, while WSM5 and SBU-YLin offer fewer predicted variables and have shorter run times. The three PBL schemes were the Mellor-Yamada-Janjić (MYJ; Janjić 1994), version 2 of the Mellor-Yamada-Nakanishi-Niino 


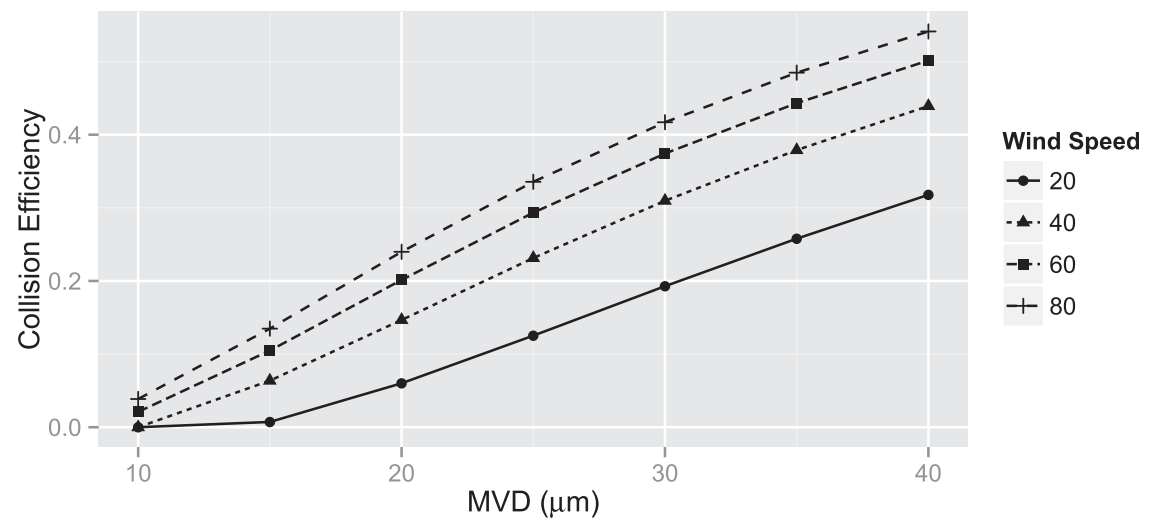

FIG. 4. Collision efficiency $\alpha_{1}$ vs MVD $(\mu \mathrm{m})$ for various wind speeds $\left(\mathrm{m} \mathrm{s}^{-1}\right)$ for a cylinder with diameter of $0.144 \mathrm{~cm}$.

(MYNN2; Nakanishi and Niino 2006), and the Yonsei University (YSU; Hong et al. 2006) schemes. Both the MYJ and the MYNN2 schemes are 1.5-order turbulent kinetic energy local closure schemes, while the YSU scheme is a nonlocal $k$-mixing scheme. Another difference is in the mixing of hydrometeors for the different schemes; in the MYNN2 scheme only the cloud water mixing ratio $Q_{c}$ is mixed, while in the YSU and the MYJ schemes both $Q_{c}$ and the cloud ice mixing ratio $Q_{i}$ are mixed. The YSU scheme was modified to correct an error found in WRF 3.4.1. This error led to higher turbulence values in stable conditions and unrealistically high wind speeds at lower levels. The YSU and MYNN2 schemes used the Monin-Obukhov scheme from the fifth-generation Pennsylvania State University-National Center for Atmospheric Research Mesoscale Model for the surface layer, while the MYJ option used its own surface layer scheme.

The MVD of a cloud has been shown to be an important parameter in ice accretion modeling due to the dependence of the collision efficiency, $\alpha_{1}$, on this term. The relationship between MVD, wind speed, and $\alpha_{1}$ is shown in Fig. 4. MVD is shown to have a larger effect on $\alpha_{1}$ at higher wind speeds. For a wind speed of $60 \mathrm{~m} \mathrm{~s}^{-1}$, similar to what is expected in the iceBlade model, $\alpha_{1}$ almost triples from 0.15 to 0.4 for MVD values between 15 and $30 \mu \mathrm{m}$. As MVD is not a prognostic variable for any of the microphysical schemes being used, several sensitivity tests were carried out to estimate its impact on the icing forecast. Both the SBU-YLin and Thompson schemes use a gamma distribution for cloud water particles. Nygaard et al. (2011) presented an equation to calculate the MVD from the gamma distribution based on the droplet concentration $N_{c}$ and cloud liquid water content $\left(\mathrm{LWC}_{c}\right)$. The WSM5 scheme uses a monodisperse cloud water distribution. Both of these distributions were tested for all three schemes to evaluate the differences. Since there were no estimates of $N_{c}$ at the evaluation site, three prescribed values were chosen as sensitivity tests: 100,250 , and $350 \mathrm{~cm}^{-3}$. The first two prescribed $N_{c}$ values are those suggested by Thompson et al. (2008) for oceanic (clean) and onshore (polluted) air, while Nygaard et al. (2011) presented several measurements of $N_{c}$ larger than $500 \mathrm{~cm}^{-3}$, suggesting a value greater than $250 \mathrm{~cm}^{-3}$ might be appropriate. The SBU-YLin and Thompson schemes were only run once with their default values for $N_{c}$ of 10 and $100 \mathrm{~cm}^{-3}$, respectively. For the monodisperse tests, fixed MVD values of $10,15,20$, and $25 \mu \mathrm{m}$ were chosen, based on the calculated MVD distributions. These distributions generally had a peak around $15 \mu \mathrm{m}$ and extended over the entire prescribed range $(10-25 \mu \mathrm{m})$.

\section{c. Coupling of iceBlade with WRF}

All of the inputs to iceBlade are from the outputs of the nine WRF sensitivity runs. The wind park covers four $10 \mathrm{~km} \times 10 \mathrm{~km}$ WRF grid cells, but in our tests there was little variation in the iceBlade results across the grid cells, so all presented results are from the northwest grid cell. Because of the high vertical resolution of the WRF model, five model levels crossed the turbines rotor plane, but as discussed in section $3 \mathrm{a}(3)$, iceBlade was designed to only use one height for input. To account for this, initial tests were conducted comparing the results from different model levels, as well as averaged values across the five levels. These results show only a minimal impact on the icing estimates, so it was decided that the WRF output would only be extracted from the model level that was approximately $80 \mathrm{~m}$ above the model terrain. The height of $80 \mathrm{~m}$ was chosen since this is the most common hub height for wind turbines and is used in current wind farm assessment studies. 
TABLE 1. Percentage of time during January 2011 with observed icing at a wind farm in central Sweden, excluding time when the turbine data were not available. Number of available time steps and total number of possible time steps are shown in parentheses, separated by a slash.

\begin{tabular}{lccr}
\hline \hline Averaging period & ANY & MOST & ALL \\
\hline 10 min $(3310 / 4608)$ & 56.44 & 29.46 & 8.67 \\
$1 \mathrm{~h}(552 / 768)$ & 57.10 & 29.35 & 9.60 \\
$8 \mathrm{~h} \mathrm{day}^{-1}(26 / 32)$ & 65.38 & 26.92 & 11.54 \\
\hline
\end{tabular}

The $\omega$ term of the Makkonen model required additional processing of the WRF outputs as a result of there being two liquid hydrometeor species, determined by size, in each of the microphysical schemes used. The cloud water mixing ratio $Q_{c}$ and rainwater mixing ratio $Q_{r}$ variables were used to calculate cloud LWC $\left(\omega_{c}\right)$ and rain LWC $\left(\omega_{r}\right)$. The cloud MVD and $\omega_{c}$ were then used to calculate the cloud collision efficiency $\alpha_{1 c}$. The total LWC $\left(\omega_{t}\right)$ was then calculated as

$$
\omega_{t}=\omega_{c} \alpha_{1 c}+\omega_{r} .
$$

The collision efficiency for rain was assumed to always be 1 , as rainwater was assumed to be collected in its entirety due to the large drop size. In Eq. (2), $\omega_{t}$ was then used to represent both the $\omega$ and $\alpha_{1}$ terms. The ambient wind speed was calculated from the $u$ and $v$ wind components that were rotated to Earth relative, and unstaggered in the horizontal.

After running iceBlade, a binary icing time series was created using a threshold of $0.001 \mathrm{~kg}$ of ice to signify ice accumulation on the blade. This threshold related well to the ANY observed icing dataset. These two datasets were used for most of the evaluation in this study.

\section{Results and discussion}

\section{a. Observed icing}

As described in section 2, an observational icing dataset was created using the turbine temperature, power production, and idealized icing threshold curve. Thus, power loss is not a term that can be examined separately under the different icing conditions since it was part of the criteria for observed icing. However, it is possible to examine the amount of time each of the turbines was iced to gain a better understanding of how the icing impacts each turbine. Table 1 shows the percentage of available times when the turbine was under icing conditions for different time intervals. The 10-min values are based on the raw values from the turbines. Hourly icing was defined by the raw turbine data extracted at the top of the hour $(0 \mathrm{~min})$. Daily icing was defined as days where eight or more hours had ice. The 10-min and hourly data have very similar percentages across all categories. This suggests that the hourly data do a reasonable job of capturing the underlying signal in the 10-min data. Daily icing events show larger percentages for the ANY and ALL categories, likely related to the 8-h threshold, but a smaller percentage of time for the MOST category. The decrease in the MOST category suggests that this group varies more throughout icing periods than does either the ANY or ALL categories.

Given the large differences among the three categories of turbine icing, the percentage of icing for each turbine was examined using the 10 -min data. It was found that the amount of icing time ranged from $17 \%$ to $43 \%$ for the various turbines with a median value of $32.6 \%$. The lowest values are found in turbines, numbered 1-5, that did not experience the same amount of icing during the early part of the month. There were between four and five widespread icing events during the month, with periods of melting between them (Fig. 3). Given the number of events, this dataset should provide a good evaluation of the icing model as it will test both the accumulation and ablation algorithms.

\section{b. Meteorological evaluation}

The WRF model outputs were evaluated for the area surrounding the wind farm using data from three surface stations located within $100 \mathrm{~km}$ of the wind park, as well as the wind park itself (Fig. 2, inset). At the wind park, temperature and wind speed were evaluated, while the surface sites also included variables allowing for the evaluation of humidity and pressure. The evaluations of wind speed, humidity, and pressure will be briefly discussed with an in-depth discussion of the temperature evaluation, because temperature is a key input to both the accretion and ablation models.

The results from the WRF model showed a moist (positive) bias at all three stations for all simulations, with the exception of those using the MYJ PBL scheme at station A. Results at station A showed the least bias across sensitivities while results from station $\mathrm{C}$ had the largest bias. This suggests there may be a temperature dependence given the orientation of the stations, with station $\mathrm{C}$ being the most northerly. The results from sensitivities using the MYJ PBL scheme consistently had the lowest humidity values for each of the microphysics schemes. The results from sensitivities using the Thompson microphysical scheme had the largest moist bias. The pressure bias was very small at less than $1 \%$ for all stations and did not show much of a signal across the different model sensitivities.

Modeled wind speeds at $10 \mathrm{~m}$ were compared at stations A, B, and C (Fig. 5). At the wind farm the modeled wind speeds were taken from the layer closest to $80 \mathrm{~m}$, the level used as input to iceBlade. At stations B and C, 


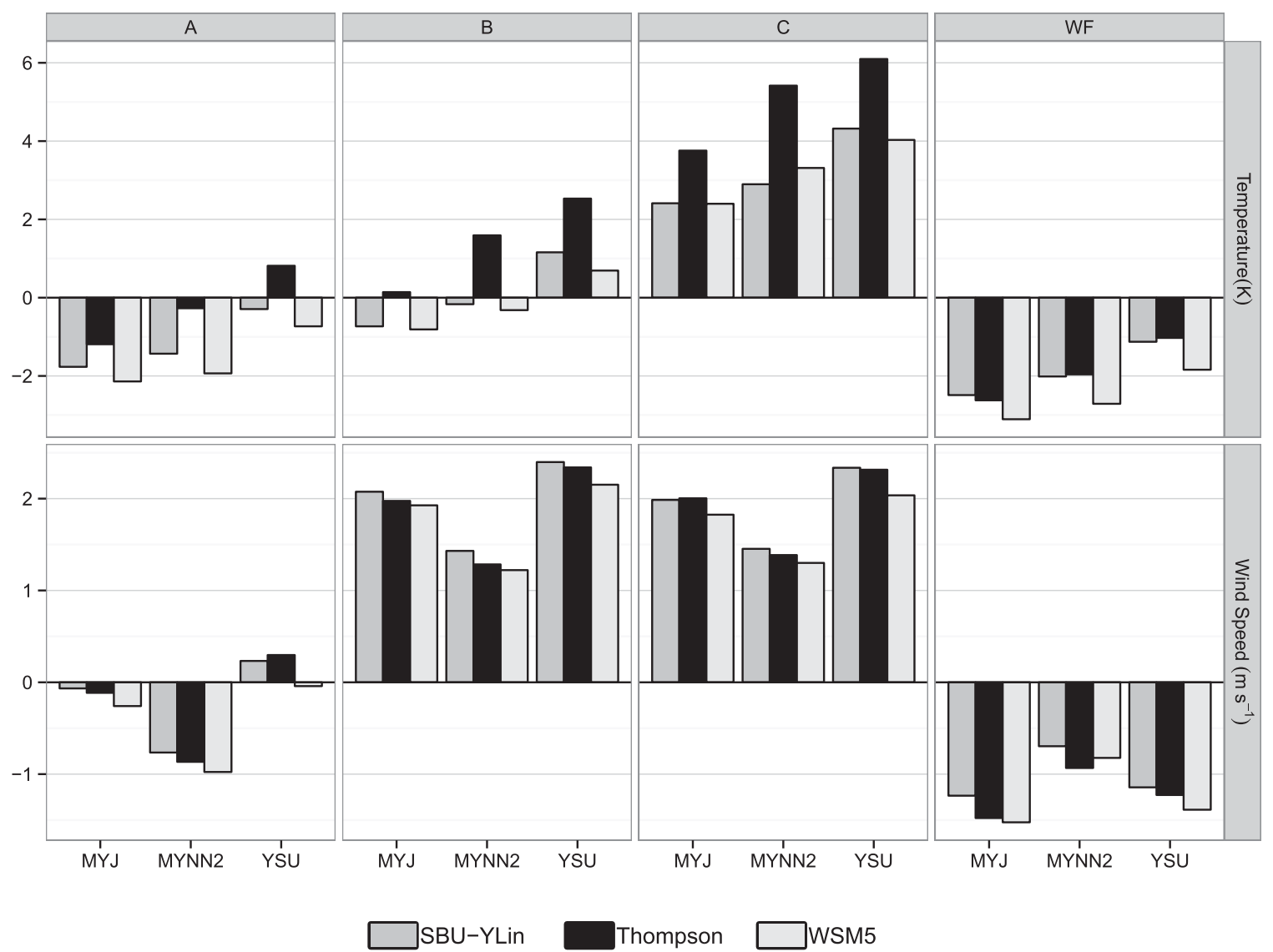

FIG. 5. Mean temperature and wind speed bias for January 2011 at each of the surface stations (A, B, C) and the wind farm (WF) for (top) temperature bias $(\mathrm{K})$ and (bottom) wind speed bias $\left(\mathrm{m} \mathrm{s}^{-1}\right)$. The two gray shades and black signify the different microphysical schemes, and the results are grouped by the PBL schemes.

the modeled bias was positive across all sensitivities while at the wind farm the bias was always negative. At station A, the results from simulations using the MYNN2 PBL scheme had a negative bias while the other two PBL schemes had a positive bias. The model results were most accurate at station $\mathrm{A}$ and at the wind farm, while at stations B and C the bias was over $100 \%$. This is not an uncommon result for 10-m wind speeds, because the observational stations are often impacted by the local characteristics of the station that are not captured by the model. For station A, which is located on a lake, these impacts should be smaller, and at the $80-\mathrm{m}$ height of the turbine there are also fewer impacts of the local surface conditions. The PBL scheme choice had the greatest impact on the $10-\mathrm{m}$ wind speed with the MYNN2 scheme consistently having slower wind speeds than the other two models. Some of these differences can be attributed to the PBL scheme's sensitivity to atmospheric stability (Draxl et al. 2014). The results across the different microphysics schemes had fairly consistent trends with the highest wind speeds occurring in simulations using the SBU-YLin scheme, while the slowest wind speeds were consistently found in results from model simulations using the WSM5 scheme. However, the differences between the microphysics schemes with a common PBL scheme were only a few percent.

Like the wind speeds, the height of the temperature measurements varied between the three meteorological stations and the wind farm. At the wind farm, data were again compared using model data extracted from the layer closest to $80 \mathrm{~m}$ while at the meteorological stations the 2-m temperature was taken from the model results. The modeled temperature bias varied the most among the variables studied across both stations and model sensitivities (Fig. 5). The largest biases are found at station C followed by those at the wind farm. Both the choice of PBL scheme and microphysical scheme had a large impact on the model's performance. At the surface stations, the results from simulations using the Thompson scheme were consistently much warmer than the results from simulations using the other microphysical schemes. 
However, at the wind farm the results from the SBU-YLin and Thompson simulations were similar while the results from the simulations using the WSM5 scheme were much cooler. The temperature time series at the wind farm showed that the mean cold bias was largely the result of the WRF model dramatically underestimating the temperature during the coldest periods of the study. The opposite was found at station $\mathrm{C}$, where the model was not able to capture the lowest temperatures. This suggests that the temperature gradient between 2 and $80 \mathrm{~m}$ may not be accurately represented in the model. However, there is also some uncertainty in the accuracy of the observed temperature from the nacelles, with reported errors of up to $2^{\circ} \mathrm{C}$ when compared with mast measurements. It is believed this may be in part due to the heating of the local atmosphere around the turbine by the electronics in the nacelle.

The variance of the temperature data was captured fairly well and the results showed good agreement for when the modeled temperature was above $0.5^{\circ} \mathrm{C}$, the key threshold for triggering shedding events in the iceBlade model. However, at temperatures just below $0^{\circ} \mathrm{C}$ there could be a rather large cold bias in the model, which would encourage more ice growth than actually occurred. This was not a significant issue since the majority of accretion periods for both the WRF model and the observed temperature were well below $-5^{\circ} \mathrm{C}$, and therefore insensitive to the temperature because all incoming particles would have frozen.

The large temperature deviations found at the wind farm are troubling from a forecasting perspective. This did not likely have a large impact on the icing forecast, since the largest deviations occurred when the temperature was below $-10^{\circ} \mathrm{C}$, which is cold enough to freeze the incoming mass flux for this study. The cold bias may have been important in the partitioning of hydrometeors between the liquid and solid phases in the various microphysics schemes, as well as the creation of clouds due to the reduced capacity of the atmosphere to hold water vapor at lower temperatures.

\section{c. Icing model comparison}

IceBlade was run using the outputs from all nine WRF sensitivity studies, using seven different distributions of MVD. Except where noted, the analysis focused on the gamma distribution of MVD using an $N_{c}$ of $250 \mathrm{~cm}^{-3}$. Throughout this section, when a specific scheme or pair of schemes is mentioned, it is in reference to the model results from a simulation using those schemes. The evaluation was performed against the ANY wind farm icing time series. The ANY time series was selected as the key variable for short-term icing forecasts is the total wind farm production.
The periods of icing from the iceBlade model results were compared to the ANY observational dataset using a contingency table method that identified four model states: 1) correct hit, 2) miss, 3) correct nonevent, and 4) false alarm. Figure 6 shows a time series of the occurrence of the contingency table. All sensitivity studies show a majority of correct forecasts. From the number of incorrect forecasts it is evident that the SBU-YLin microphysical scheme and the YSU PBL scheme produce fewer icing events than the other schemes do. The YSU results are likely due to the warmer temperatures produced in that scheme. The most common type of incorrect forecast (miss or false alarm) varies between the different WRF sensitivities, suggesting that the choice of optimal scheme will depend on which incorrect forecast type is more important. For example, the Thompson-MYNN2 results have few missed cases but a large number of false alarm cases. Meanwhile, the SBUYLin-MYJ results show very few false alarms but many misses.

Figure 7 shows the hit and false alarm rates for each of the sensitivity tests using different values of $N_{c}$ to calculate the MVD based on the function from Nygaard et al. (2011). Several simulations have hit rates over 0.8 and the Thompson-MYNN2 hit rate is close to 1.0. The high hit rate values correspond to sensitivity tests that produce more icing, as these simulations also have false alarm rates over 0.2. The choice of $N_{c}$ had little impact on either the hit rate or the false alarm rate. This suggests that the periods of icing were independent of this value despite its impact on the MVD distribution. As MVD was expected to have a large impact on icing accumulation, this result was surprising but can be explained by examining the time series of the ice mass (Fig. 8).

Figure 8 shows the accumulated ice mass over time for all of the monodisperse MVD values and the $250 N_{c}$ gamma-distributed MVDs. The ice accumulates at different rates depending on the MVD value, leading to large differences in ice amounts. However, since the ice removal was dominated by shedding events, the difference in ice amount did not translate to the duration of the events. It should be noted that these results may change if the assumed distribution in the microphysical schemes were changed, rather than only imposing the new MVD in the iceBlade model, as this could feed back into the amount of liquid water and types of hydrometeors predicted by the model. This may also explain some of the differences between the Thompson and SBU-YLin schemes, as there was an order of magnitude difference in their $N_{c}$ values.

For simulations using a monodisperse MVD of $10 \mu \mathrm{m}$, the ice growth was minimal, causing events that were 

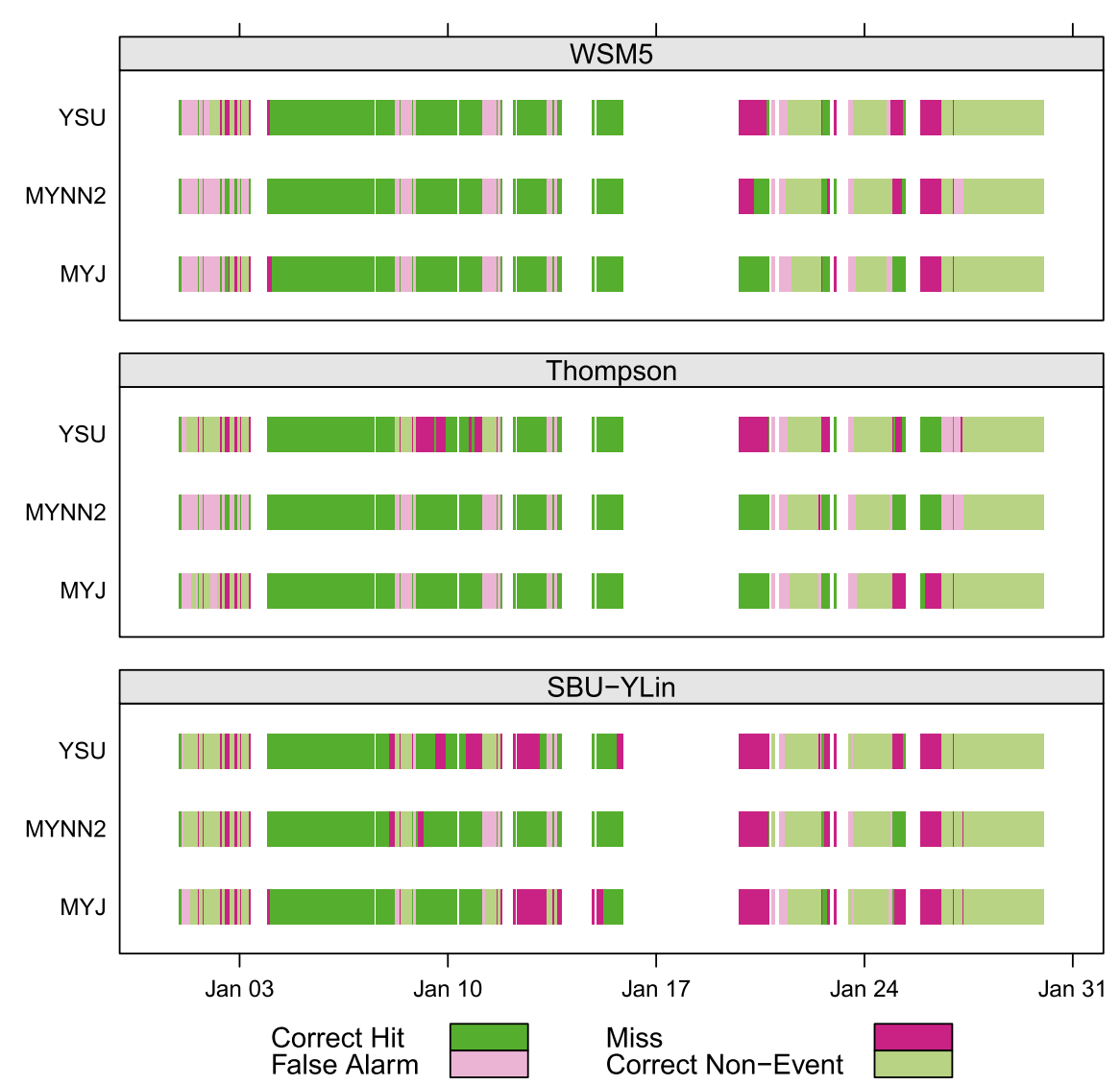

FIG. 6. Comparison of modeled and observed icing periods from the ANY dataset as a function of (top to bottom) microphysics and, within each microphysics scheme, the YSU, MYNN2, and MYJ PBL schemes. The color codes match the entries of a contingency table (not shown); green denotes good predictions, and pink denotes poor predictions. White space denotes either missing or removed data.

shorter in duration than the other MVD values. However, when using larger MVD values the duration of icing is almost identical, despite the large differences in ice mass. For the largest prescribed MVD $(25 \mu \mathrm{m})$ the ice mass grows to a value almost 3 times larger than in the $15-\mu \mathrm{m}$ test. The gamma distributed MVD often shows lower ice mass than any but the smallest of the prescribed MVD cases. This result was expected, as the distribution of the gamma-distributed MVD had a peak near $15 \mu \mathrm{m}$.

The ice-mass analysis also aids in our understanding of the differences in the icing event time series (Fig. 6). The increased number of missed events in the SBU-YLin simulations was caused by reduced accumulation during active icing periods. The lower ice accumulation led to the removal of ice earlier via the sublimation process; unlike in the other schemes where the ice was only removed by the total shedding events. This led to the large number of misses at the end of the icing events in the SBU-YLin sensitivity tests.
While the choice of microphysical scheme had a significant impact on the model performance, it is particularly interesting to examine the difference between the PBL schemes with the same microphysical schemes. The YSU scheme produced many more missed events, regardless of the microphysical scheme being used, while also generating lower ice masses throughout the period. This was a result of increased sublimation-approximately double that of the other two schemes, caused by the higher temperatures found in the YSU scheme. The temperature difference between the three PBL schemes also had a large impact on the ice accumulation, as the coldest scheme, MYJ, forecast more ice accumulation over the month than either of the other schemes.

To further evaluate the model performance, iceBlade was compared against three other icing duration forecasts. The first was the iceBlade model run on a standard cylinder, which is similar to the approach taken by Byrkjedal (2012a); however, as iceBlade does not 

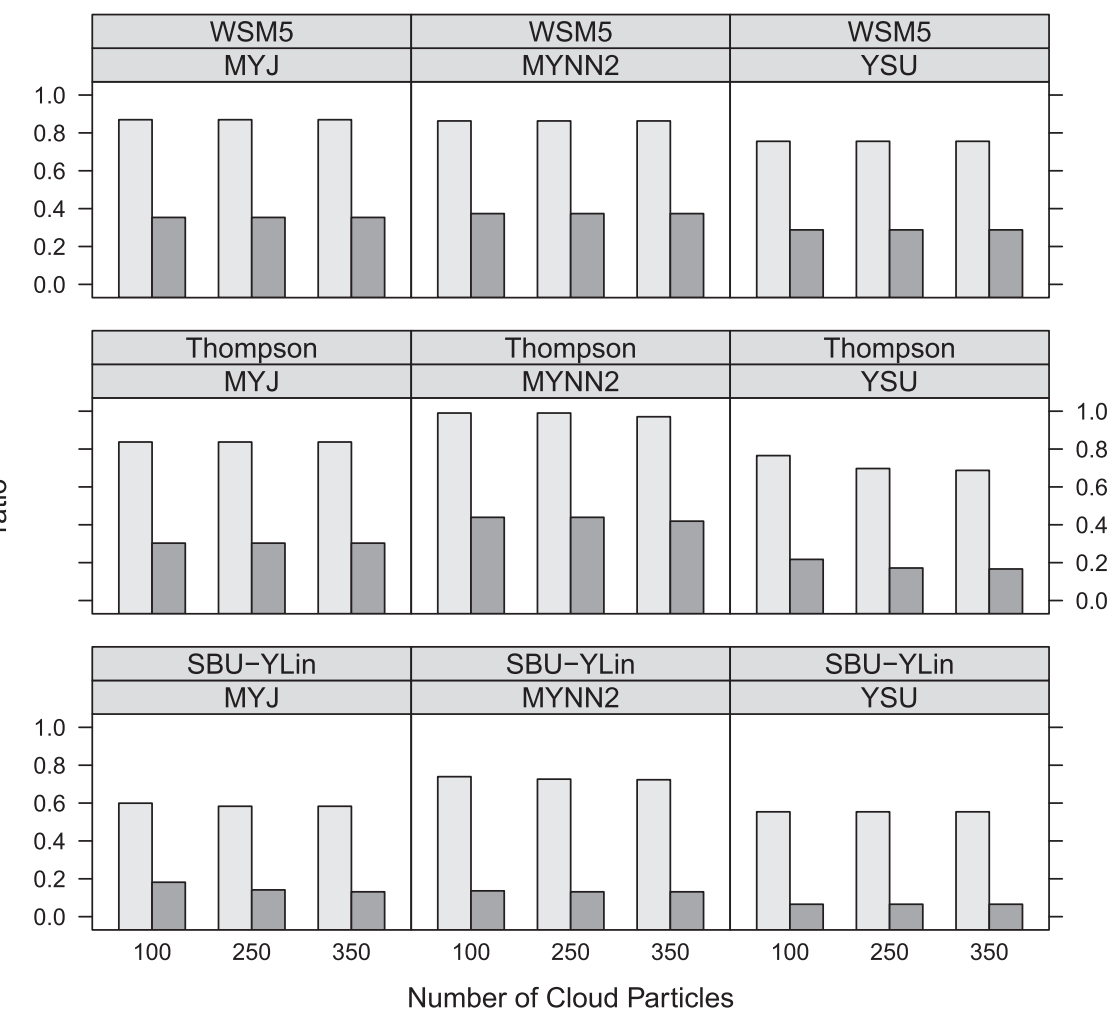

Hit Rate $\square \quad$ False Alarm Rate

FIG. 7. Sensitivity of the hit and false alarm rates as a function of the $N_{c}$ parameter used to calculate the MVD for all nine WRF simulations at the grid cell containing the wind farm.

increase the size of the cylinder as the ice grows, it can be assumed that the cylinder results are overestimated when compared with the standard Makkonen model, because the increased cylinder size would reduce the collision efficiency. The second alternative model was a threshold-based model that has been used at Vestas to estimate the periods of icing on turbines for annual energy estimates. The threshold used here forecast icing when the temperature was below $0^{\circ} \mathrm{C}$ and the sum of the mixing ratios of $Q_{c}$ and $Q_{r}$ was above $0.05 \mathrm{~g} \mathrm{~kg}^{-1}$. The final alternative model was the persistence model described in section 2 .

To compare the different icing models, several skill scores commonly used in meteorological forecast evaluation (Wilks 2006) were selected: the Heidke skill score (HSS), Kuiper skill score (KSS), threat score (TS), Pierce skill score (PSS), and equitable threat score (ETS). The skill scores present different views of the model's performance: HSS shows the fractional improvement in the proportion of correct forecasts over chance, KSS is the difference between the hit rate and false alarm rate, and PSS is the difference between the miss rate and the false alarm rate. TS and ETS relate the number of hits to the sum of all observations with the exception of correct nonevents, where ETS offsets the tendency of TS to be influenced by the climatology of the event by subtracting the hits expected by chance from both the numerator and the denominator. For all of these scores, 1 is the best possible forecast.

In almost all cases, the results from iceBlade are shown to outperform those from the other models (Fig. 9). The threshold method is shown to perform very poorly in this evaluation, because it does not include a persistence term for leaving ice on the blade after an accretion event. As expected from the results in Byrkjedal (2012a), the standard cylinder does not show much skill in estimating the periods of icing identified by the power production curve. This is largely due to the small amount of ice accretion that occurs on the standard cylinder allowing for rapid ice removal by sublimation. The lower ice accretion on the standard cylinder is most likely due to the large difference between the ambient wind speed and the relative wind speed of the blade. The persistence model performs almost as well as the iceBlade model, as was expected due to the relatively long periods of the icing and no-icing events. During transition seasons or at 

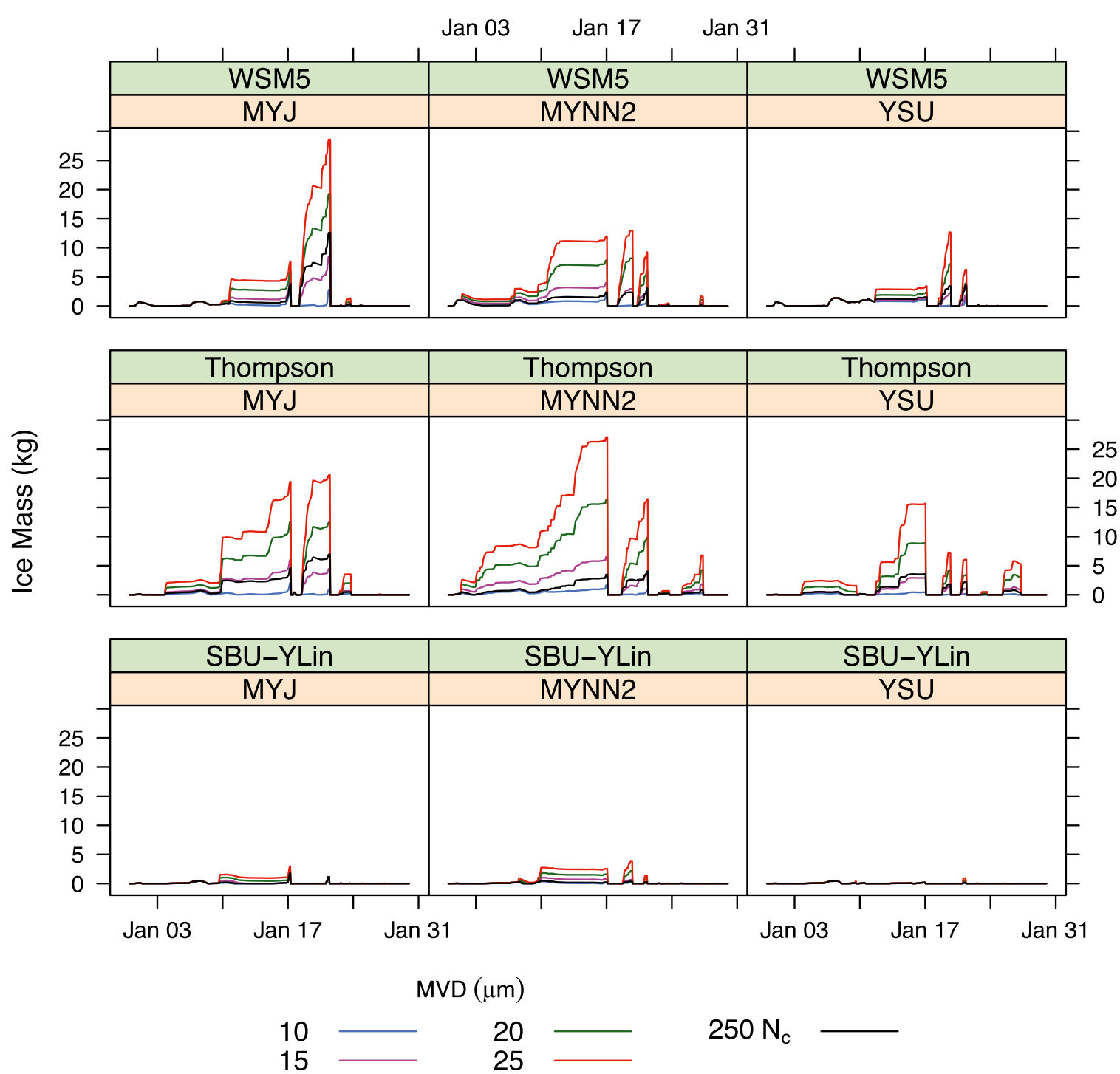

FIG. 8. Time series of total accumulated ice mass $(\mathrm{kg})$ from beginning of the modeling period for each of the nine WRF simulations at the grid cell containing the wind farm. Different colors indicate the various prescribed MVD values. The black line signifies the calculated MVD with an $N_{c}$ set to $250 \mathrm{~cm}^{-3}$.

a location that experiences shorter icing events, the persistence model would likely not perform as well, while the skill of iceBlade in these conditions is currently unknown. In comparing the different mesoscale model sensitivities, the SBU-YLin microphysical scheme and the YSU PBL scheme both perform worse across simulations compared with the other schemes. The differences between PBL schemes are smaller than those across the microphysical schemes and the Thompson-MYNN2 setup slightly outperforms the other schemes overall; however, either the MYJ or MYNN2 scheme coupled with the Thompson or WSM5 scheme seems to be an appropriate choice for this location.
The precipitation and cloud properties of each model simulation were compared to better understand the differences in icing amounts between the WRF sensitivity studies. The precipitation rate, timing (Fig. 10), and accumulation were similar across all nine simulations. Total monthly precipitation varied by less than $10 \%$ of the monthly precipitation total across the nine simulations, with the lowest precipitation values being in the WSM5-YSU and Thompson-MYJ cases. The total precipitation value includes rain, snow, and graupel from both the microphysical and convective schemes; however, for this period the convective precipitation contributed less than $1 \%$ of the total precipitation. 

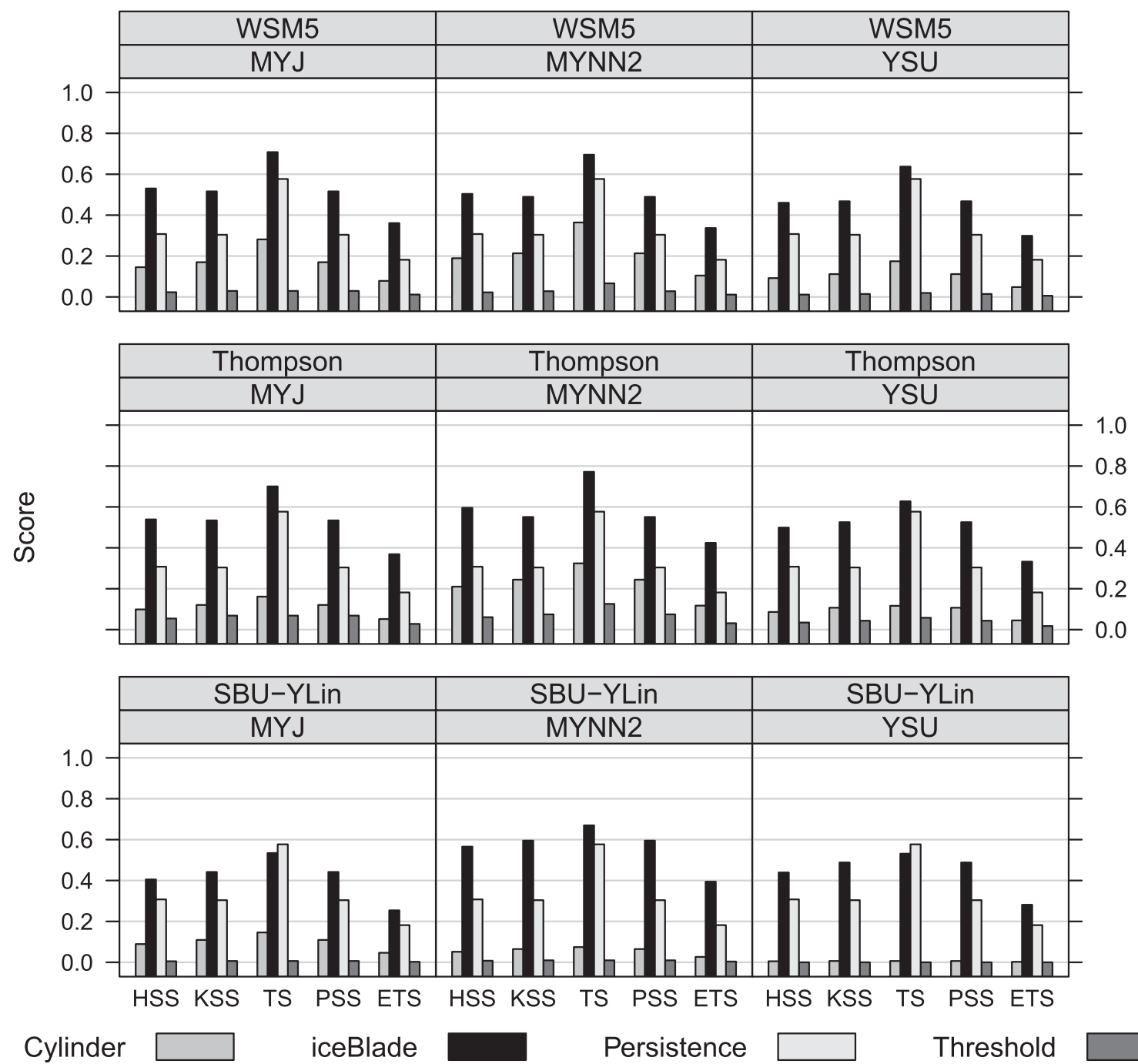

FIG. 9. Model skill scores for iceBlade run on a standard cylinder, iceBlade, a 1-day persistence forecast, and a threshold method for the nine WRF sensitivities at the grid cell containing the wind farm. The skill scores shown are HSS, KSS, TS, PSS, and ETS, calculated using the verification package of the $\mathrm{R}$ software.

Given the similar monthly precipitation amounts, selecting the correct physics options for icing is not possible based on precipitation alone. This is due to the icing model relying on the accurate prediction of all clouds, not just precipitating clouds.

Figure 11 shows the total hydrometeor mixing ratio separated into the four relevant hydrometeor types from each of the nine model simulations. The cloud parameters provide a better match to the iceBlade results than was found with the precipitation rates, as SBU-YLin clearly has a smaller total hydrometeor mixing ratio at $80 \mathrm{~m}$. This suggests that the SBU-YLin scheme may precipitate the cloud more rapidly, due to the similar precipitation (Fig. 10) and reduced cloud. The SBU-YLin scheme was found to also have the lowest amount of liquid-phase hydrometeors $\left(Q_{c}+Q_{r}\right)$. Since the iceBlade model only includes liquid hydrometeors, this points directly to the reduction of icing periods in the SBU-YLin sensitivity tests. It is also interesting that the WSM5 microphysical scheme is the only microphysical scheme to produce any significant cloud ice $\left(Q_{i}\right)$ at this height, suggesting either a reduction in $Q_{c}$ or $Q_{s}$ compared with the other two schemes. The increased $Q_{i}$ in the WSM5 scheme suggests that cloud ice is more readily formed at warmer temperatures in the WSM5 scheme, and that $Q_{i}$ is slower to accumulate to the snow phase and form $Q_{s}$. The Thompson scheme shows less $Q_{r}$ than do either of the other two schemes but much larger $Q_{c}$ amounts. This balance between the $Q_{c}$ and $Q_{r}$ hydrometeor classes could explain the similarities between the 

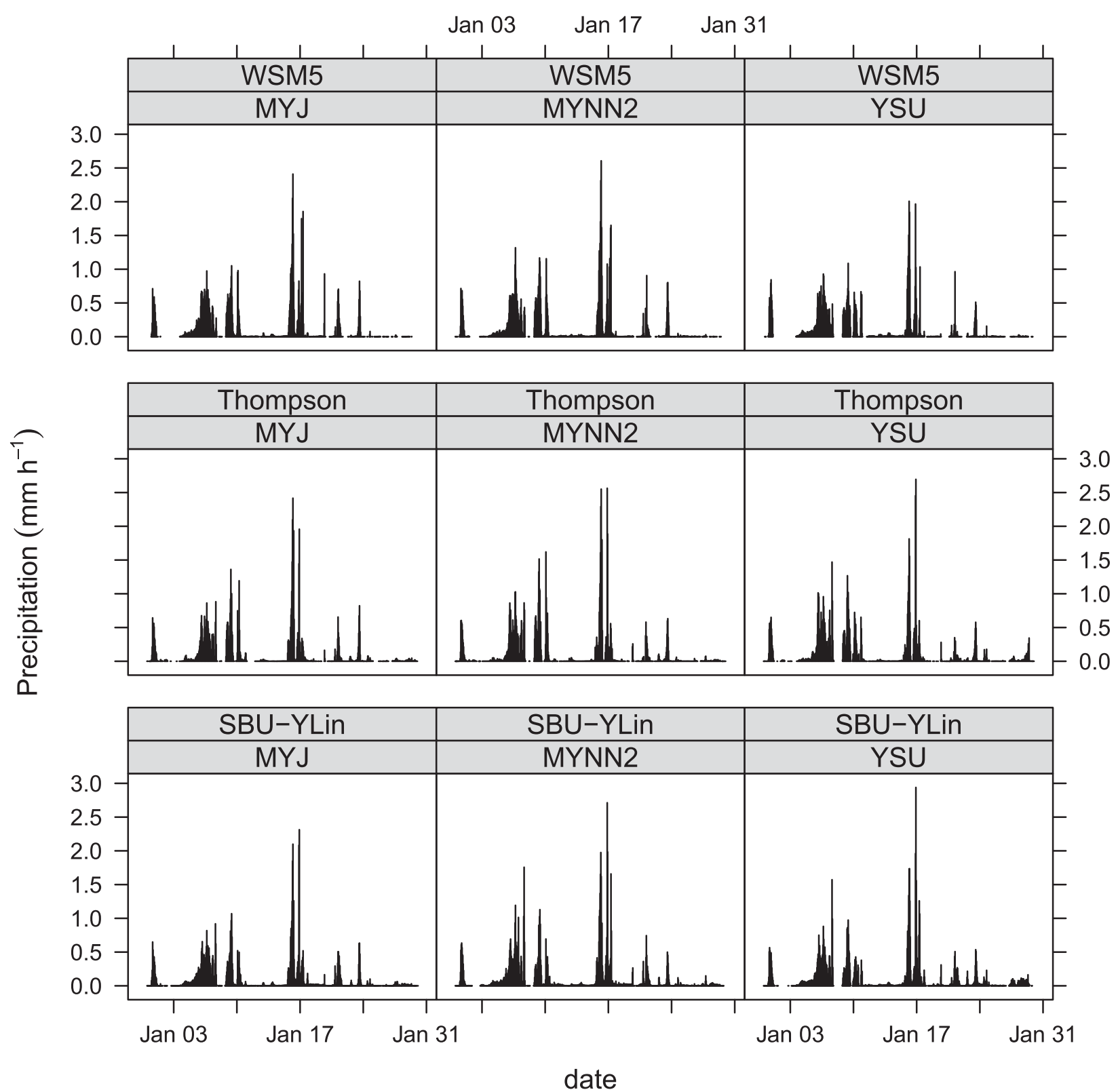

FIG. 10. Time series of total hourly precipitation rate $\left(\mathrm{mm} \mathrm{h}^{-1}\right)$ from each of the nine WRF simulations at the grid cell containing the wind farm.

icing forecasts of the WSM5- and Thompson-driven sensitivities, due to the high collision efficiency of $Q_{r}$. The reduced precipitation and $Q_{r}$ in the Thompson scheme could also be due to the higher $N_{c}$ parameter relative to the SBU-YLin scheme, which would lead to smaller cloud droplets, as the larger cloud water droplets in the SBU-YLin scheme should more rapidly convert to precipitation.

This study did not focus on forecasting the atmospheric conditions, but instead was run using a hindcast approach to determine if the method of coupling iceBlade to WRF was feasible at this station. The performance in a forecasting mode is somewhat uncertain, as the additional uncertainties in the meteorological data, due to uncertainties in the input conditions, would suggest a decrease in model performance. However, as energy forecasts are typically produced only for 1-2 days into the future, the results may also be improved. Additionally, this station was located in relatively flat terrain, allowing for a coarser resolution to provide reasonable cloud parameters. It is expected that in areas with increased topographical complexity, the model resolution will become more important for determining the correct timing and magnitude of cloud events. 

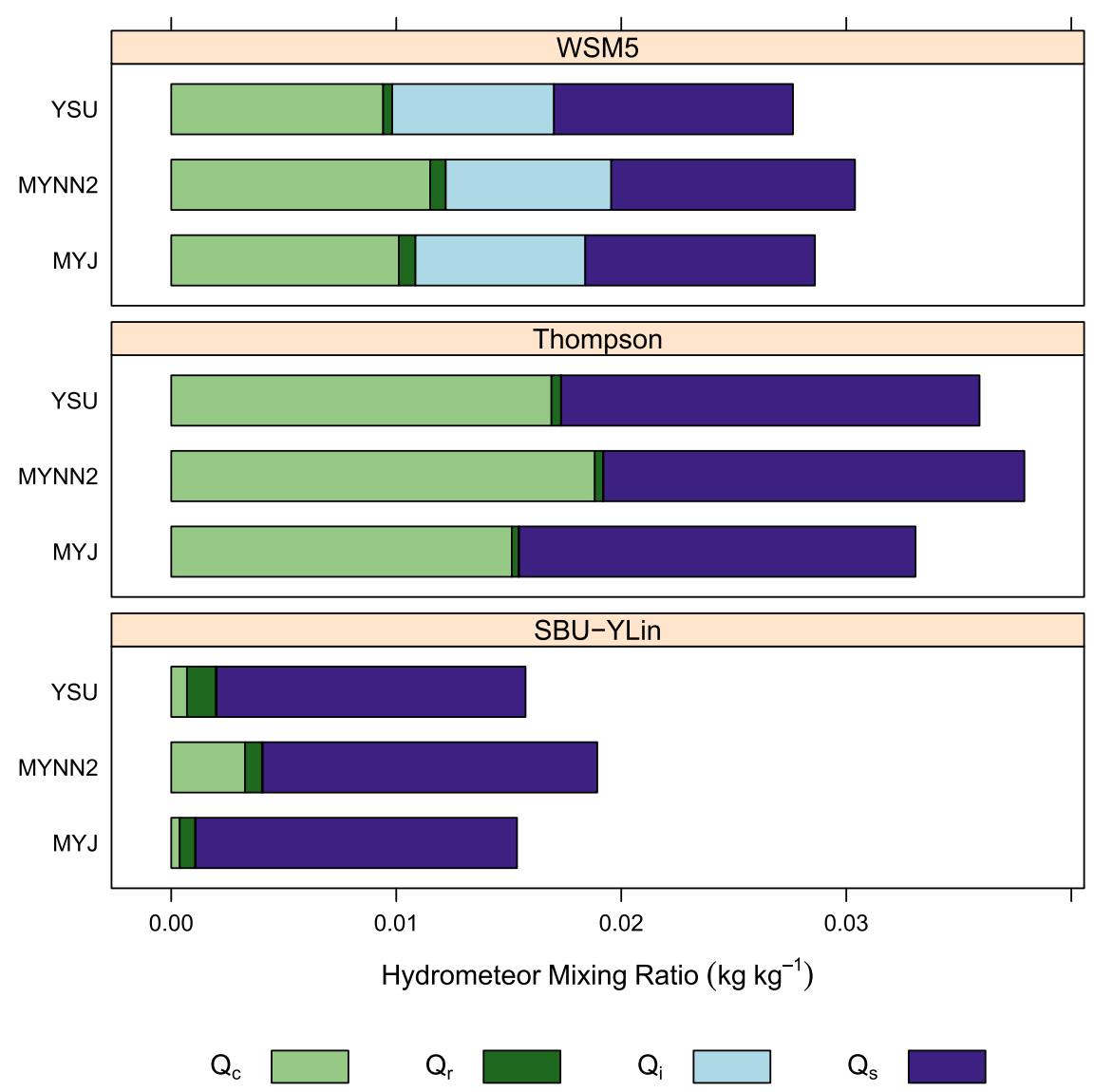

FIG. 11. Monthly sum of cloud mixing ratio $\left(\mathrm{kg} \mathrm{kg}^{-1}\right)$ by hydrometeor type for each of the nine WRF simulations at the grid cell containing the wind farm at $80 \mathrm{~m}$ AGL. The darker colors identify larger hydrometeors (rain and snow). The hydrometeors from WRF are cloud droplets $\left(Q_{c}\right)$, rain $\left(Q_{r}\right)$, ice $\left(Q_{i}\right)$, and snow $\left(Q_{s}\right)$.

\section{Conclusions}

This study has shown that iceBlade, driven by outputs from the WRF model, can provide improved forecasts of icing on a wind turbine blade compared to a persistence model, a threshold-based method, and a standard cylinder model. The observed icing dataset, created using a relationship between the observed and idealized power output and the observed nacelle temperature, allowed for the evaluation to focus on icing that impacted the turbine performance. The comparison with the cylinder approach demonstrated that the increased effective wind speed of a rotating turbine blade contributes greatly to the icing duration and improves model performance.

The choice of microphysical and PBL schemes in the WRF model were found to have a large impact on the estimated ice mass, and a smaller but still significant impact on icing duration, even when the models largely agree on the forecast precipitation. Therefore, an evaluation of precipitation is unlikely to be meaningful when selecting the model schemes for an icing forecast. This was due to the importance of the accurate forecast of both the amount and partitioning of hydrometeors in the microphysical schemes, rather than the precipitation rate. For the PBL schemes, the temperature difference was the main cause of variations in icing forecasts. In addition to the atmospheric model physics themselves, the ice-mass forecast by iceBlade was shown to be very sensitive to the MVD distribution used for $Q_{c}$. It seems the approach used by Nygaard et al. (2011) performed well for this study and would continue to be a good starting point for future studies for all three of the microphysical schemes presented here.

The results suggest that the iceBlade model is capable of providing short-term icing forecasts at this location that could aid in day-to-day decision making, such as pricing on the energy market or when to enable deicing or anti-icing systems. Given a long enough meteorological simulation, the iceBlade model has the potential to be used for developing icing climatologies, which 
would aid the wind energy industry in the key areas of site selection, maintenance planning, cost-benefit analysis, and deployment of deicing and anti-icing systems.

Acknowledgments. This work was supported financially by the Top-Level Research Initiative (TFI) project, Improved Forecast of Wind, Waves and Icing (IceWind), Vestas Wind Systems A/S, and the Nordic Energy Industry. The atmospheric data for input and boundary conditions for this study are available from the Research Data Archive (RDA), which is maintained by the Computational and Information Systems Laboratory (CISL) at the National Center for Atmospheric Research (NCAR). NCAR is sponsored by the National Science Foundation (NSF). The original data are available from the RDA (http://dss.ucar.edu) in dataset ds083.2. The authors thank Greg Thompson and the anonymous reviewers of this manuscript for their valuable comments and suggestions that greatly improved the quality of this contribution.

\section{REFERENCES}

Antoniou, I., S. M. Pedersen, and P. B. Enevoldsen, 2009: Wind shear and uncertainties in power curve measurement and wind resources. Wind Eng., 33, 449-468.

Barber, S., Y. Wang, S. Jafari, N. Chokani, and R. S. Abhari, 2011: The impact of ice formation on wind turbine performance and aerodynamics. J. Sol. Energy Eng., 133, 011007, doi:10.1115/ 1.4003187.

Bernstein, B. C., J. Hirvonen, E. Gregow, and I. Wittmeyer, 2012: Experiences from real-time LAPS-LOWICE runs over Sweden: 2011-2012 icing season. Winterwind Int. Wind Energy Conf., Skellefteå, Sweden, Swedish Wind Power Association. [Available online at http://www.slideshare.net/ WinterwindConference/3a-bernstein-lapslowice.]

Bragg, M., A. Broeren, and L. Blumenthal, 2005: Iced-airfoil aerodynamics. Prog. Aerosp. Sci., 41, 323-362.

Byrkjedal, O., 2012a: Mapping of icing in Sweden-On the influence from icing on wind energy production. Winterwind Int. Wind Energy Conf., Skellefteå, Sweden, Swedish Wind Power Association. [Available online at http://www.slideshare.net/ WinterwindConference/3a-byrkjedal-icingkvt.]

- 2012b: The benefits of forecasting icing on wind energy production. Winterwind Int. Wind Energy Conf., Skellefteå, Sweden, Swedish Wind Power Association. [Available online at http:// www.slideshare.net/WinterwindConference/3-forecast-kvt.]

Cattin, R., S. Kunz, A. Heimo, G. Russi, M. Russi, and M. Tiefgraber, 2007: Wind turbine ice throw studies in the Swiss Alps. European Wind Energy Conf., Vol. 1, Milan, Italy, European Wind Energy Association, 3-7.

Chen, F., and J. Dudhia, 2001: Coupling an advanced land surfacehydrology model with the Penn State-NCAR MM5 modeling system. Part II: Preliminary model validation. Mon. Wea. Rev., 129, 587-604.

Dierer, S., R. Oechslin, and R. Cattin, 2011: Wind turbines in icing conditions: Performance and prediction. Adv. Sci. Res., 6, 245250 .
Draxl, C., A. N. Hahmann, A. Peña, and G. Giebel, 2014: Evaluating winds and vertical wind shear from Weather Research and Forecasting model forecasts using seven planetary boundary layer schemes. Wind Energy, 17, 39-55.

Dudhia, J., 1989: Numerical study of convection observed during the Winter Monsoon Experiment using a mesoscale twodimensional model. J. Atmos. Sci., 46, 3077-3107.

Farzaneh, M., Ed., 2008: Atmospheric Icing of Power Networks. Springer, $381 \mathrm{pp}$.

Fikke, S., and Coauthors, 2006: COST 727: Atmospheric icing on structures measurements and data collection on icing: State of the art. MeteoSwiss Tech. Rep. 75, 110 pp.

— J. E. Kristjánsson, and B. E. K. Nygaard, 2008: Modern meteorology and atmospheric icing. Atmospheric Icing of Power Networks, M. Farzaneh, Ed., Springer, 1-29.

Finstad, K. J., E. P. Lozowski, and E. M. Gates, 1988: A computational investigation of water droplet trajectories. J. Atmos. Oceanic Technol., 5, 160-170.

Gent, R. W., N. P. Dart, and J. T. Cansdale, 2000: Aircraft icing. Philos. Trans. Roy. Soc., 358A, 2873-2911.

Hau, E., 2013: Wind turbine economics. Wind Turbines: Fundamentals, Technologies, Application, Economics, 3rd, translated ed., Springer, 845-870.

Homola, M. C., T. Wallenius, L. Makkonen, P. J. Nicklasson, and P. A. Sundsb $\varnothing, 2010 \mathrm{a}$ : The relationship between chord length and rime icing on wind turbines. Wind Energy, 13, 627-632.

,,,--- - $\longrightarrow$, and,$- 2010 \mathrm{~b}$ : Turbine size and temperature dependence of icing on wind turbine blades. Wind Eng., 34, 615-627.

— M. S. Virk, P. J. Nicklasson, and P. A. Sundsbø, 2012: Performance losses due to ice accretion for a $5 \mathrm{MW}$ wind turbine. Wind Energy, 15, 379-389.

Hong, S.-Y., J. Dudhia, and S.-H. Chen, 2004: A revised approach to ice microphysical processes for the bulk parameterization of clouds and precipitation. Mon. Wea. Rev., 132, 103-120.

—, Y. Noh, and J. Dudhia, 2006: A new vertical diffusion package with an explicit treatment of entrainment processes. Mon. Wea. Rev., 134, 2318-2341.

Janjić, Z. I., 1994: The step-mountain eta coordinate model: Further developments of the convection, viscous sublayer, and turbulence closure schemes. Mon. Wea. Rev., 122, 927945.

Jonkman, J., S. Butterfield, W. Musial, and G. Scott, 2009: Definition of a 5-MW reference wind turbine for offshore system development. National Renewable Energy Laboratory Tech. Rep. NREL/TP-500-38060, 75 pp. [Available online at mhk. pnnl.gov/wiki/images/b/bb/Jonkman_et_al_2009.pdf.]

Kain, J. S., 2004: The Kain-Fritsch convective parameterization: An update. J. Appl. Meteor., 43, 170-181.

Langmuir, I., and K. Blodgett, 1961: A mathematical investigation of water droplet trajectories. Collected Works of Irving Langmuir, Vol. 10, C. G. Suits, Ed., Pergamon Press, 10, 348393.

Lin, Y., and B. A. Colle, 2011: A new bulk microphysical scheme that includes riming intensity and temperature-dependent ice characteristics. Mon. Wea. Rev., 139, 1013-1035.

Makkonen, L., 2000: Models for the growth of rime, glaze, icicles and wet snow on structures. Philos. Trans. Roy. Soc., 358A, 2913-2939.

_ - T. Laakso, M. Marjaniemi, and K. J. Finstad, 2001: Modelling and prevention of ice accretion on wind turbines. Wind Eng., 25, 3-21. 
Mlawer, E. J., S. J. Taubman, P. D. Brown, M. J. Iacono, and S. a. Clough, 1997: Radiative transfer for inhomogeneous atmospheres: RRTM, a validated correlated- $k$ model for the longwave. J. Geophys. Res., 102 (D14), 16663-16682.

Nakanishi, M., and H. Niino, 2006: An improved Mellor-Yamada level-3 model: Its numerical stability and application to a regional prediction of advection fog. Bound-Layer Meteor., 119, 397-407.

Nygaard, B. E. K., J. E. Kristjánsson, and L. Makkonen, 2011: Prediction of in-cloud icing conditions at ground level using the WRF model. J. Appl. Meteor. Climatol., 50, 2445-2459.

Pruppacher, H. R., and J. D. Klett, 2004: Microphysics of Clouds and Precipitation. 2nd ed. Kluwer Academic, 975 pp.

Reynolds, R. W., T. M. Smith, C. Liu, D. B. Chelton, K. S. Casey, and M. G. Schlax, 2007: Daily high-resolution-blended analyses for sea surface temperature. J. Climate, 20, 5473-5496.

Ronsten, G., and Coauthors, 2012: State-of-the-art of wind energy in cold climates. IEA Wind Task 19, $67 \mathrm{pp}$. [Available online at http://arcticwind.vtt.fi/reports/Task19_SotA_WEinCC_ 2012_approved.pdf.]

Seifert, H., A. Westerhellweg, and J. Kröning, 2003: Risk analysis of ice throw from wind turbines. Boreas VI, Pyhä, Finland, Finnish Meteorological Institute, 18 pp. [Available online at http://s3.amazonaws.com/windaction/attachments/999/ RiskAnalysisofIceThrow-SeifertPapers.pdf.]

Sherif, S., N. Pasumarthi, and C. Bartlett, 1997: A semi-empirical model for heat transfer and ice accretion on aircraft wings in supercooled clouds. Cold Reg. Sci. Technol., 26, 165-179.

Skamarock, W. C., and Coauthors, 2008: A description of the Advanced Research WRF version 3. NCAR Tech. Note NCAR/TN-475+STR, 113 pp. [Available online at www. mmm.ucar.edu/wrf/users/docs/arw_v3.pdf.]

Soderberg, S., and M. Baltscheffsky, 2012: Long-term estimates and variability of production losses in icing climates. Winterwind Int.
Wind Energy Conf., Skellefteå, Sweden, Swedish Wind Power Association. [Available online at http://www.slideshare.net/ WinterwindConference/longterm-estimates-and-variability-ofproduction-losses-in-icing-climates-stefan-sderberg-magnusbaltscheffsky-weathertech-scandinavia.]

Srivastava, R. C., and J. L. Coen, 1992: New explicit equations for the accurate calculation of the growth and evaporation of hydrometeors by the diffusion of water vapor. J. Atmos. Sci., 49, 1643-1651.

Thompson, G., R. T. Bruintjes, B. G. Brown, and F. Hage, 1997: Intercomparison of in-flight icing algorithms. Part I: WISP94 Real-Time Icing Prediction and Evaluation Program. Wea. Forecasting, 12, 878-889.

— P. R. Field, R. M. Rasmussen, and W. D. Hall, 2008: Explicit forecasts of winter precipitation using an improved bulk microphysics scheme. Part II: Implementation of a new snow parameterization. Mon. Wea. Rev., 136, 5095-5115.

Troen, I., and E. Petersen, 1989: European Wind Atlas. Ris $\varnothing \mathrm{Na}-$ tional Laboratory, Roskilde, Denmark, 656 pp.

Virk, M. S., M. C. Homola, and P. J. Nicklasson, 2010: Relation between angle of attack and atmospheric ice accretion on large wind turbine's blade. Wind Eng., 34, 607-613.

,-- , and - 2012: Atmospheric icing on large wind turbine blades. Int. J. Energy Environ., 3, 1-8.

Wilks, D. S., 2006: Statistical Methods in the Atmospheric Science. 2nd ed. Academic Press, 627 pp.

Wolff, C., F. McDonough, M. Politovich, and G. Cunning, 2009: Forecast icing product: Recent upgrades and improvements. First AIAA Atmospheric and Space Environments Conf., San Antonio, Texas, American Institute of Aeronautics and Astronautics, Paper AIAA 2009-3531.

Yang, J., 2012: Simulation of icing events over Gaspé region. Winterwind Int. Wind Energy Conf., Skellefteå, Sweden, Swedish Wind Power Association. [Available online at http:// www.slideshare.net/WinterwindConference/3a-jing-yang.] 